\title{
The Effects of Mat Pilates on Weight-Bearing Symmetry, Balance, And Respiratory Function in A Young Woman with Scoliosis
}

\author{
Kristen L Moore* \\ Physical Therapist, Azusa Pacific University, USA \\ Submission: October 11, 2019; Published: November 01, 2019 \\ *Corresponding author: Kristen L Moore, Physical Therapist, Azusa Pacific University, Azusa, USA
}

\begin{abstract}
Background: Research has shown that adolescent idiopathic scoliosis (AIS) is the most common form of scoliosis. This diagnosis manifests itself in the form of asymmetries of the chest wall and ribs, increased pain, decreased self-image, and reduced quality of life. Depending on spinal curvature severity, or Cobb angle, AIS is treated through observation, orthotic bracing, scoliosis-specific exercises (SSE), or surgery. Despite various treatment options, most AIS cases continue into adulthood. Purpose. The goal of this study was to evaluate the usefulness of a mat Pilates intervention in treating a young woman with scoliosis. The mat Pilates intervention was compared to conventional treatments such as orthotic bracing and SSE as described in the reviewed articles.
\end{abstract}

Literature review: A comprehensive review of research performed within the last 10 years was conducted, with 38 articles reviewed in full text. In general, research is mostly aimed at treating adolescents whose spines are still growing and maturing, with very few studies performed on adults with scoliosis. Although the current literature supports the use of exercises to treat this population, no single regimen prevailed amongst others. Furthermore, most efforts are targeted toward reducing Cobb angle rather than treating the whole patient.

Case description: The patient was a 24-year-old female graduate student who diagnosed with scoliosis at age 16. She presented to physical therapy with a left thoracolumbar curvature of approximately $25^{\circ}$, postural and functional asymmetries, reduced quality of life, increased pain, impaired respiratory muscle strength, and reduced chest wall mobility.

Discussion: The findings of this study suggest that mat Pilates can be a very useful intervention for young adults with scoliosis as improvements in respiratory muscle strength, chest wall mobility, balance, weight-distribution while squatting, and pain levels were all achieved. Keywords: Adolescent idiopathic scoliosis; AIS; Scoliosis specific exercises; SSE; Cobb angle; Pilates

Abbreviations: AIS: Adolescent Idiopathic Scoliosis; SSE: Scoliosis-Specific Exercises; QOL: Quality of Life; SLS: Single Limb Stance; LE: Lower Extremity

\section{Introduction}

Adolescent idiopathic scoliosis (AIS) is a disease affecting $3 \%$ of adolescents worldwide that is defined by a $\geq 10^{\circ}$ coronal plane curvature of the spine Gallant et al. [1] Most diagnosed individuals experience manifestations of AIS such as postural asymmetries, reduced pulmonary function, higher prevalence of pain, decreased self-image, and reduced quality of life (QOL) into [2]. The purpose of this study was to evaluate the effects of a mat Pilates intervention on the functional symmetry, pulmonary function, balance, and QOL of a young woman with AIS as compared to orthotic bracing. Chapter two contains a review of the current literature on AIS and available forms of treatment. The literature shows that orthotic bracing and scoliosis-specific exercises (SSE) are the most popular forms of treatment for moderate scoliosis, which is defined as a $25^{\circ}-45^{\circ}$ curvature [2]. The benefits of orthotic bracing are controversial, mainly because of low patient adherence and potential adverse effects such as reduced vital capacity and QOL [2,3]. Furthermore, this form of treatment requires individuals to wear a brace 23 hours a day, which can be challenging for adolescents in their impressionable ages $[4,2]$.

In addition, there are a wide variety of SSE interventions available, but evidence supporting the administration of these interventions is low [5]. These exercises were often aimed at 
reducing the degree of spinal curvature in adolescents, which is much less likely after skeletal maturity is reached. Moreover, studies reported that some SSE interventions had similar results to Pilates [5]. Research has yet to specifically address respiratory dysfunction, reduced QOL, asymmetries while squatting, and imbalance in young adults with scoliosis [6]. Chapter three is a case report describing a young woman diagnosed with AIS at age 16 which she did not receive thorough treatment for. The patient's QOL, pulmonary function, balance, and functional symmetry were measured before and after a four-week mat Pilates intervention. The tests showed significant improvement in right lower extremity function, with an increase in right single limb stance (SLS) time and a restoration of functional symmetry during a squat. Respiratory muscle strength also significantly improved following treatment. Chapter four discusses the results and the clinical implications of this study. Additionally, limitations of this report and suggestions for future research are also explained.

\section{Case Report}

The subject of this case study was a 24-year-old Caucasian female who was diagnosed with AIS at age 16. Her diagnosis was thoracolumbar levoscoliosis (Figures 1,2). The subject began to experience low back pain when she was in high school after she became heavily involved in sports such as basketball and track, as well as other forms of exercise. Her chief complaints included pain during prolonged sitting or standing, with $7 / 10$ pain when maintaining a position for more than 45 minutes. She complained of pain when transitioning from sitting to standing after sitting for a long time as well. She also reported that extension-based activities provoked her back pain the most. Another limitation the patient mentioned was her inability to perform a back squat with more than 85 pounds without pain. Her final complaint was that her respiratory function occasionally limited the amount of rigorous physical activity she could perform. The patient's impairments are described in the International Classification of Functioning, Disability and Health (ICF) model shown in (Figure $3)$.

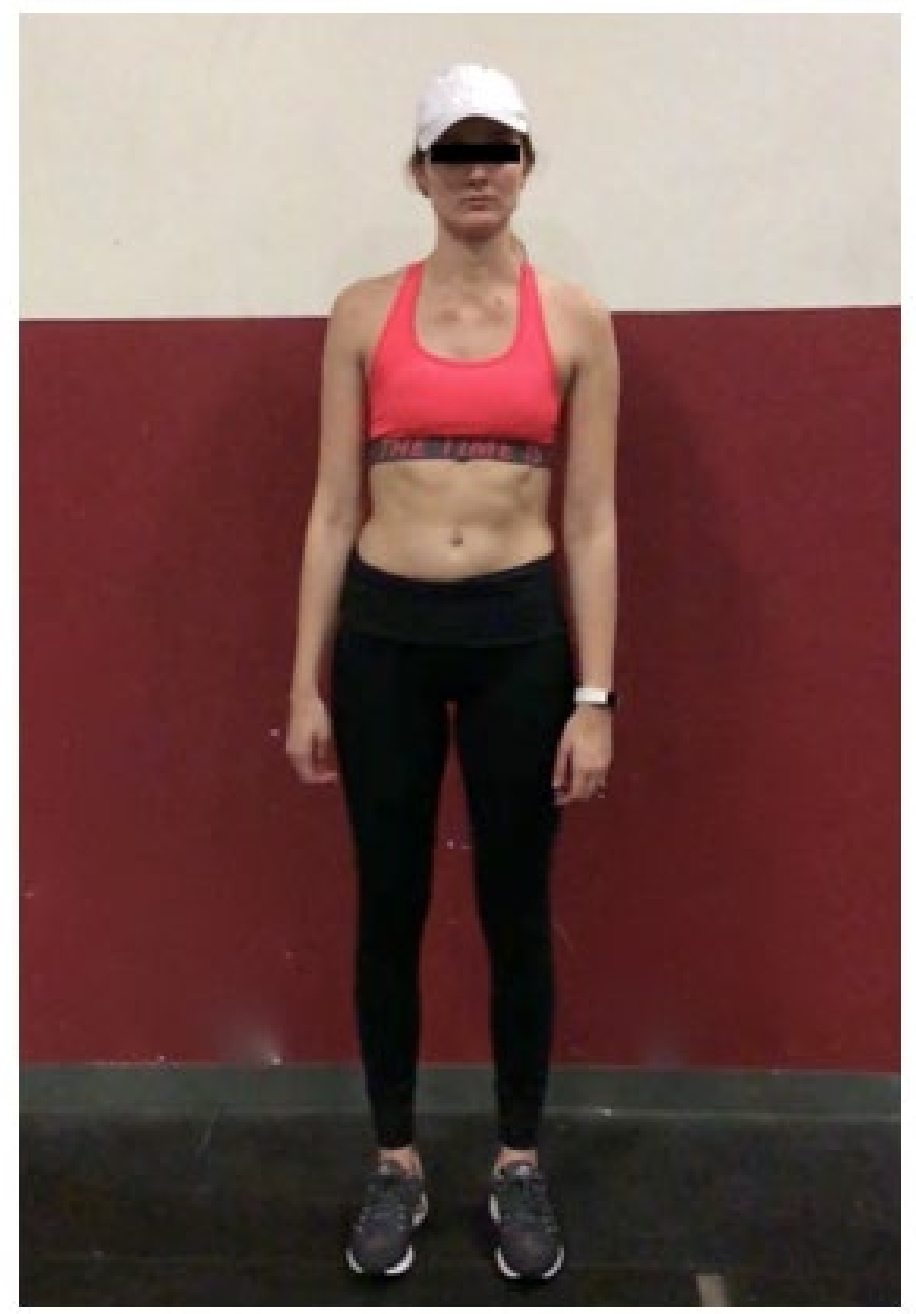

Figure 1: Standing Posture: Anterior. 


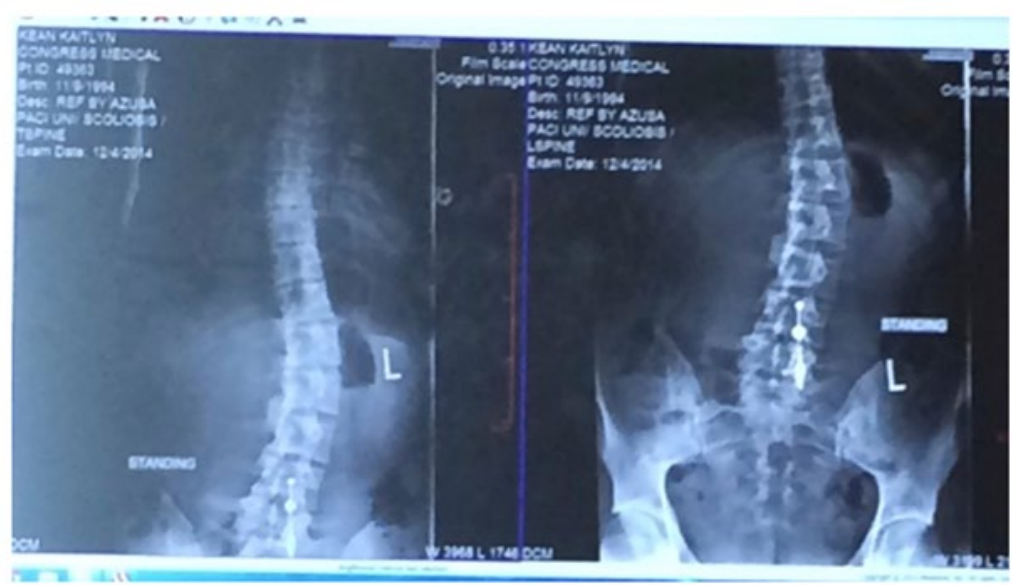

Figure 2: Radiograph of Patient's Levo Scoliotic Curvature.

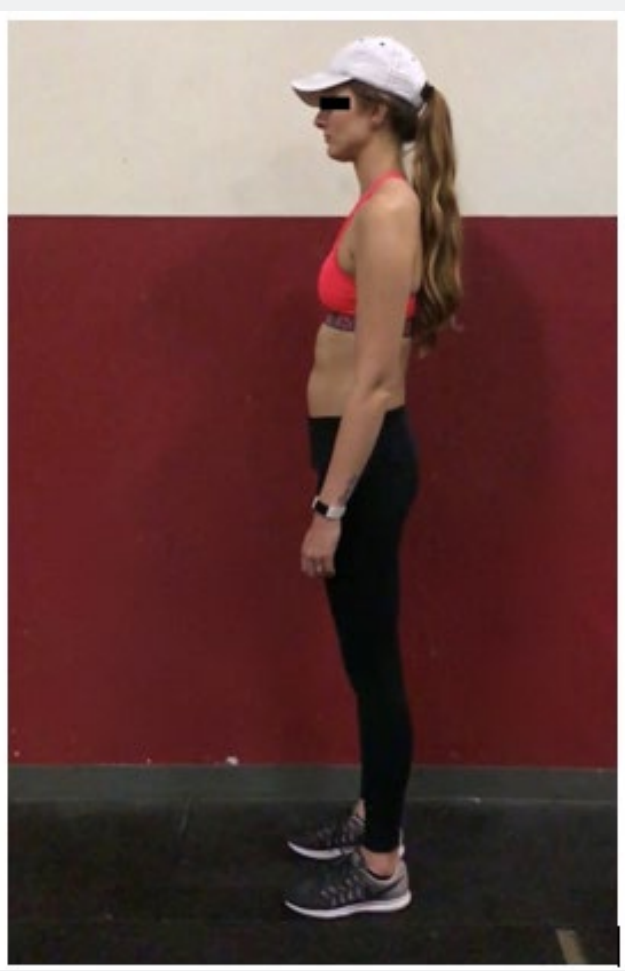

Figure 3: Standing Posture: Lateral View.

Her past medical history included two surgeries to correct her pes excavatum: one when she was nine years old, which was deemed unsuccessful, and another when she was 11 years old. She was also diagnosed with exercise-induced asthma as a teenager, for which she was prescribed an inhaler. The patient reported seldom using her inhaler for respiration, roughly one time a month. Overall, this patient was a healthy individual who sustained a moderately active lifestyle. This patient had never undergone physical therapy for her condition, but she came to therapy readily seeking treatment to achieve her goals. Her goals for physical therapy included: improving her overall endurance in various positions, such as sitting in class or standing at work, being able to tolerate sitting and standing for one hour and being able to transition into standing without pain. Additionally, she desired to achieve better postural awareness and symmetry in standing and other activities. She also stated a desire to improve her respiratory function, which would allow her to exercise more vigorously with fewer breaks.

\section{Clinical Impression 1}

This patient was a good candidate for mat Pilates intervention as she lives a moderately active lifestyle and does 
not have other concerning medical conditions. Therefore, she was able to safely perform all the activities administered to her. Her back pain had been consistent throughout her teenage and young-adult years without any acute exacerbation of symptoms. She also demonstrated an eagerness for treatment as she desired to achieve goals and improve her daily life. The patient's primary complaints consisted of low back pain, reduced respiratory function, and pain-limited squats, which led the researcher to believe mat Pilates would be an appropriate intervention. Additionally, the nature of her condition, including reduced spinal mobility and stability, muscular imbalances, and postural asymmetries were also indications that mat Pilates would benefit this patient. Further examination was performed to ensure the eligibility of this patient to begin a mat Pilates protocol.

\section{Examination}

To confirm impaired respiratory functioning, asymmetries, impaired balance, decreased quality of life (QOL) and reduced spinal range of motion, a variety of tests were performed.

\section{Posture}

A standing posture analysis was performed to gain greater insight into potential impairments (Figures 1,3). The following were noted during observation: reduced thoracic flexion, reduced lumbar lordosis, posterior pelvic tilt, bilateral knee hyperextension, bilateral hip extension, and thoracolumbar levoscoliosis.

\section{Respiratory function}

Because of the patient's breathing challenges during vigorous activity, respiratory muscle strength was measured. A Dwyer Magnehelic device was used to assess the patient's maximal inspiratory pressure (MIP) and maximal expiratory pressure (MEP) with inter-rater reliability scores of 0.88 and 0.87 , respectively. Three trials were performed, and the average was recorded as the final measurement. Results are shown in (Table 1). The patient's average MIP was $75.0 \mathrm{~cm}$ of $\mathrm{H} 2 \mathrm{O}$ and her average MEP was $78.3 \mathrm{~cm}$ of H2O. According to Sclauser Pessoa et al. [7], the normative MIP value for women 18-29 years of age is $97 \mathrm{~cm} \mathrm{H} 2 \mathrm{O}$ with a $95 \%$ confidence interval of 88.6-105.4 $\mathrm{cm}$ H2O. An age-normalized MEP value was not available, so the normative MEP was calculated using equations reported by Evans \& Whitelaw [8]. The following equations for MEP and the lower limit of normal (LLN) were utilized: MEP = 131- $(0.86$ $\mathrm{x}$ age); LLN = 95- (0.57 $\mathrm{x}$ age). The calculated MEP norm for a 24-year-old female was $110.4 \mathrm{~cm} \mathrm{H2O}$, with calculated LLN being $81.32 \mathrm{~cm} \mathrm{H} 20$. This indicates that the patient's respiratory muscle strength was $29 \%$ and $41 \%$ below the MIP and MEP norms, respectively (Table 1).

In addition to respiratory muscle assessment, chest mobility was measured with a tape measure. Chest wall expansion (CWE) is the difference in thorax circumference between maximal inhalation and exhalation, and was recorded in centimeters at the upper, middle, and lower chest (axilla, xiphoid process, and midway between the xiphoid and umbilicus, respectively). The literature reports reliability values between 0.78 and 0.83 for the upper chest and 0.82 to 0.84 for the lower chest, but no values were found for the middle chest. After three measurements in each location, the averages for chest expansion were $2.50 \mathrm{~cm}$, $5.75 \mathrm{~cm}$, and $2.50 \mathrm{~cm}$ for the upper, middle, and lower chest, respectively [9]. reported that adequate chest mobility should be $2.88 \mathrm{~cm}$ for the upper chest, $2.97 \mathrm{~cm}$ for the middle chest, and $3.07 \mathrm{~cm}$ for the lower chest. Therefore, this patient has reduced mobility in her upper and lower chest, but excessive mobility in her middle chest (Table 1).

Table 1: Outcome Measures at Initial Evaluation and One Day After Intervention.

\begin{tabular}{|c|c|c|c|}
\hline Measurement & Initial Evaluation & Follow-up Evaluation & Normal Population \\
\hline Maximal inspiratory pressure (MIP) & $75.0 \mathrm{~cm} \mathrm{H}_{2} 0$ & $92.3 \mathrm{~cm} \mathrm{H}_{2} 0$ & $97 \mathrm{~cm} \mathrm{H}_{2} \mathrm{O}$ \\
\hline Maximal expiratory pressure (MEP) & $78.3 \mathrm{~cm} \mathrm{H}_{2} 0$ & $90 \mathrm{~cm} \mathrm{H}_{2} 0$ & $110.4 \mathrm{~cm} \mathrm{H}_{2} 0$ \\
\hline \multirow{3}{*}{ Chest wall expansion } & Upper: $2.5 \mathrm{~cm}$ & Upper: $3.8 \mathrm{~cm}$ & Upper: $2.54 \mathrm{~cm}$ \\
\hline & Middle: $5.75 \mathrm{~cm}$ & Middle: $5.2 \mathrm{~cm}$ & Middle: $3.175 \mathrm{~cm}$ \\
\hline & Lower: $2.5 \mathrm{~cm}$ & Lower: $3.5 \mathrm{~cm}$ & Lower: $5.08 \mathrm{~cm}$ \\
\hline Weight distribution during bodyweight squat & 30:70 (L: R) & 50:50 (L: R) & 50:50:00 \\
\hline Weight distribution during weighted squat & 30:70 (L: R) & $48: 52$ (L: R) & 50:50:00 \\
\hline \multirow{2}{*}{ Single limb stance with eyes closed } & Right: $7.9 \mathrm{sec}$ & Right: $14.0 \mathrm{sec}$ & $28.8 \pm \sec$ \\
\hline & Left: $12.8 \mathrm{sec}$ & Left: $15.0 \mathrm{sec}$ & \\
\hline Quality of life (SF-36) & 83.2 & 85.4 & 100 \\
\hline
\end{tabular}

Note: During Weighted Squats, A 15-Pound Weighted Ball Was Placed in The Patient's Hands; SF-36: Short Form- 36 Questionnaire; Sec:

Seconds; L: Left; R: Right.

\section{Balance and Symmetry}

Spinal curvature can cause not only visual asymmetries, but measurable asymmetries as well. To quantify the patient's lack of symmetry during a squatting task, the researcher used two kinematics force plates and the Video 3D database for quantitative analysis. Two force plates made by the Arizona 
Medical Training Institute were used side by side with the patient's right foot on one and her left foot on the other, with feet placed $38 \mathrm{~cm}$ apart. There were no reliability or validity measures in the literature for this assessment. Three trials of both bodyweight squats and weighted squats were performed. The weighted squats performed the same way as bodyweight squats, but with the patient holding a 15-pound ball in her hands. The ratio of the average weight distribution during the patient's squat was 0.30 to 0.70 (right to left) as shown in (Table 1). Thus, this patient regularly applied $70 \%$ of her weight through her left lower extremity (LE) during the squatting task.

The same kinematics system was used to measure balance. The patient was asked to perform a single limb stance (SLS) with her arms folded across her chest while standing on the force plate for 30 seconds. This procedure was then repeated on the opposite leg. The amount of sway in the medial-lateral direction during the patient's stance was recorded and analyzed using Video 3D software. The purpose of this test was to determine if stability on the left limb was different from that on the right limb and to detect any signs of balance deficits in general [10]. Reliability of the root mean squared (RMS) distance traveled in the medial-lateral (ML) direction was 0.60 as reported by Da Silva et al. [11] as displayed in (Table 2). The average sway during the patient's left SLS was $4.36 \mathrm{~mm}$ from her center of pressure (CoP), whereas the average CoP during her right SLS was $4.05 \mathrm{~mm}$. Total excursion was also detected during this activity, measuring the total distance the patient's CoP traveled during the SLS. The total excursion was $942.3 \mathrm{~mm}$ and $988.8 \mathrm{~mm}$ on her left and right LE, respectively (Table 3).

Table 2: Pre and Post Balance Measures During Single Limb Stance.

\begin{tabular}{|c|c|c|c|}
\hline & Pre: Left SLS & Post: Left SLS & Pre: Right SLS \\
\hline Mean distance (CoP) & $4.36 \mathrm{~mm}$ & $5.39 \mathrm{~mm}$ & $4.05 \mathrm{~mm}$ \\
\hline Total excursion & $942.28 \mathrm{~mm}$ & $829.62 \mathrm{~mm}$ & $988.81 \mathrm{~mm}$ \\
\hline Mean velocity & $942.40 \mathrm{~mm}$ & $832.39 \mathrm{~mm}$ & $98.31 \mathrm{~mm} \mathrm{~mm}$ \\
\hline
\end{tabular}

Note: SLS: Single Limb Stance; Cop: Center of Pressure.

Table 3: Exercise Intervention Performed Three Times A Week.

\begin{tabular}{|c|c|}
\hline \multirow{3}{*}{ Warm up-to mobilize the pelvis, activate the abdominals, and activate the multifidus muscles } & 1. Pelvic clocks \\
\hline & 2. The hundred \\
\hline & 3. The swimming \\
\hline \multirow{3}{*}{ Exercises-to restore thoracic kyphosis and increase flexibility of the posterior aspect of the spine } & 1. Cat and cow \\
\hline & 2. Standing roll down \\
\hline & 3. Spine stretch \\
\hline \multirow{8}{*}{$\begin{array}{l}\text { Asymmetrical exercises-to promote equal use of the muscles on the convex and concave sides of the } \\
\text { spine }\end{array}$} & 1. Single leg stretch \\
\hline & 2. 90-90: side to side \\
\hline & 3. Mermaid \\
\hline & 4. Quadruped twist \\
\hline & 5. Quadruped bird-dog \\
\hline & 6. Side plank mermaid \\
\hline & 7. Unilateral bridges \\
\hline & 8. Dead bug with single leg tap down \\
\hline $\begin{array}{l}\text { Symmetrical exercises-to incorporate the use of core stabilizers equally on both sides with segmen- } \\
\text { tal mobility of the spine }\end{array}$ & 1. Roll up \\
\hline
\end{tabular}

SLS was utilized again with the patient's eyes closed to determine how long she could stand on each limb. Measurements were taken in seconds, to the tenth of a second. The timer was stopped when the patient exhibited significant trunk movement, LE movement, or if one of the patient's LEs touched the other. The normative value for the SLS test in individuals 20-29 years of age is $28.8 \pm 2.3$ seconds [12]. The patient achieved 7.9 seconds on her right LE and 12.8 seconds on her left LE, indicating that her single-limb balance was well below average (Table 1).

\section{Quality of Life Questionnaire}

QOL is a crucial aspect to treatment, especially for chronic conditions where complete improvement is unattainable. QOL can be measured using a variety of questionnaires, but the survey chosen for this study was the Short Form 36 (SF-36) as it is the most widely evaluated standard health measure and has reliability measures ranging from 0.83 to 0.91 for different parameters (Table 2). The SF-36 contains eight subcategories of well-being, including physical role limitations, body pain, general 


\section{Journal of Yoga and Physiotherapy}

health perceptions, energy and vitality, social functioning, emotional role limitations, and mental health. Each of these domains demonstrate adequate internal validity of $>0.7$ [13]. The total score the patient achieved on the SF-36 at the initial evaluation was 83.2 out of 100 (Table 1).

\section{Clinical Impression \#2}

Based on the examination data outlined in Table $1 \& 3$, this young woman was deemed appropriate for the mat Pilates intervention to address her impairments. These included unequal weight-bearing during squatting tasks, reduced inspiratory and expiratory pressure, decreased upper and lower chest mobility, and balance deficits. Deficits such as decreased tolerance to prolonged positions, increased prevalence of pain, and difficulty breathing during vigorous activities were reported by the patient. Postural asymmetries were observed in the patient's standing posture as well (Figures 1-3).

A post-test examination was completed at the end of the four-week intervention. All areas previously addressed were measured again the day after the final day of treatment.
The hypothesis of this study was that the patient would have improved symmetry during a squat, reduced total excursion during SLS, greater respiratory muscle functioning, and increased chest wall mobility, as well as improved QOL scores at the four-week follow-up testing.

\section{Intervention}

The mat Pilates intervention consisted of twelve sessions over the course of four weeks (three sessions per week). Previous research and a certified Pilates instructor were referenced to develop the specific protocol. The certified Pilates instructor was also present to ensure proper form during the exercises, including adequate spinal elongation and appropriate breathing. The protocol was initiated on March 28, 2019 and ended on April 25, 2019. Each session was completed in an environment that promoted concentration and focus, either at a park or inside a gym. The length of the sessions varied between 30 to 45 minutes depending on the amount of time used to complete all repetitions. Each session began with educating the patient on the six principles of Pilates: centering, concentration, control, precision, fluidity, and diaphragmatic breathing.

Table 4: Intervention with Clinical Reasoning.

\begin{tabular}{|c|c|c|c|}
\hline Exercise & Repetitions & Breaths & Short Term Goal \\
\hline Pelvic clocks & $\begin{array}{l}1-12 \times 2 \text { clockwise, } 1-12 \times \\
2 \text { counterclockwise }\end{array}$ & 2 sets of 24 breaths, 1 breath per each hour & Mobilization of the pelvis. \\
\hline Hundred & $\begin{array}{l}\text { Static hold of } 90-90 \text { posi- } \\
\text { tion with } 100 \text { beats with } \\
\text { arms }\end{array}$ & 10 breaths total, 1 breath per 10 beats with arms & TA activation. \\
\hline Swimming & $\begin{array}{l}100 \text { alternating limb } \\
\text { extensions }\end{array}$ & 10 breaths total, 1 breath per 10 limb alternations & MF activation. \\
\hline Cat and cow & 10 of each & 10 breaths total, inhale upon spine extension, exhale upon spine flexion & $\begin{array}{l}\text { Mobilization of the spine and } \\
\text { stretch of posterior chain mus- } \\
\text { culature. }\end{array}$ \\
\hline $\begin{array}{l}\text { Standing roll down } \\
\text { stretch }\end{array}$ & 10 & $\begin{array}{l}20 \text { breaths; inhale upon bilateral shoulder flexion; exhale during roll } \\
\text { down; inhale at bottom; exhale upon roll up }\end{array}$ & $\begin{array}{l}\text { Increased segmental mobility of } \\
\text { the spine and stretching of poste- } \\
\text { rior chain musculature. }\end{array}$ \\
\hline Spine stretch & 10 each way & $\begin{array}{l}50 \text { breaths, } 5 \text { per repetition; inhale in initial upright posture; exhale with } \\
\text { forward fold; inhale during rotation; exhale to complete rotation; inhale } \\
\text { into elongated aspect of rib cage; exhale to maximize rotation; inhale } \\
\text { during transition to other side; exhale during rotation; inhale into elon- } \\
\text { gated aspect of thorax; exhale to maximize rotation; inhale back to center; } \\
\text { exhale as spine is elongated in upright position }\end{array}$ & $\begin{array}{l}\text { Spinal elongation and rotation, } \\
\text { increased flexibility of the poste- } \\
\text { rior musculature, and expansion } \\
\text { of the rib cage, bilaterally. }\end{array}$ \\
\hline Single leg stretch & 10 on each leg & $\begin{array}{l}20 \text { breaths, } 2 \text { per repetition; exhale during hip flexion and hamstring } \\
\text { stretch; inhale during transition to opposite leg }\end{array}$ & $\begin{array}{l}\text { Maintenance of TA activation } \\
\text { increase flexibility of bilateral } \\
\text { hamstrings and improve motor } \\
\text { control }\end{array}$ \\
\hline 90-90: Side to side & 10 in each direction & $\begin{array}{l}20 \text { breaths, } 2 \text { per repetition; inhale as knees slowly fall to one side, exhale } \\
\text { to bring knees back to center }\end{array}$ & $\begin{array}{l}\text { Maintenance of TA, MF, IO, and } \\
\text { EO activation, increase spinal } \\
\text { stability during a rotational exer- } \\
\text { cise utilizing both concentric and } \\
\text { eccentric muscle contractions }\end{array}$ \\
\hline Mermaid & 10 in each direction & $\begin{array}{c}40 \text { breaths, } 2 \text { breaths per repetition on each side; inhale during initiation } \\
\text { of lateral flexion; exhale during spinal rotation and to complete lateral } \\
\text { elongation; inhale during lateral flexion back to center; exhale during } \\
\text { stretch of opposite lateral musculature }\end{array}$ & $\begin{array}{l}\text { Focus on principles of control, } \\
\text { fluidity and breathing. Increased } \\
\text { eccentric control of spinal stabi- } \\
\text { lizers, unilateral spinal elonga- } \\
\text { tion and rib cage expansion }\end{array}$ \\
\hline
\end{tabular}




\section{Journal of Yoga and Physiotherapy}

\begin{tabular}{|c|c|c|c|}
\hline Quadruped twist & 10 in each direction & $\begin{array}{c}40 \text { breaths, } 2 \text { breaths per repetition on each side; inhale as arm crosses } \\
\text { midline; exhale during spinal rotation; inhale into elongated thorax; exhale } \\
\text { to maximize rotation; inhale to transition to contralateral side and to } \\
\text { repeat breathing series }\end{array}$ & $\begin{array}{l}\text { To utilize breath to expand rib } \\
\text { cage, stretch shortened muscu- } \\
\text { lature of the thorax and improve } \\
\text { vertebral mobility }\end{array}$ \\
\hline $\begin{array}{l}\text { Quadruped bird- } \\
\qquad \text { dog }\end{array}$ & 10 on each side & $\begin{array}{l}20 \text { breaths, } 1 \text { per repetition on each side; exhale during limb extension; } \\
\text { inhale to return to center }\end{array}$ & $\begin{array}{l}\text { Maintenance of spinal elongation } \\
\text { and activation of spinal stabiliz- } \\
\text { ers to while opposing limbs are } \\
\text { extended. }\end{array}$ \\
\hline $\begin{array}{l}\text { Side plank mer- } \\
\text { maid }\end{array}$ & 10 on each side & $\begin{array}{c}20 \text { breaths, } 1 \text { per repetition on each side; inhale to extend arm up and over } \\
\text { head as hips lift off the ground; exhale as hips lower back down and arm } \\
\text { returns to side }\end{array}$ & $\begin{array}{l}\text { Increased strength of core mus- } \\
\text { culature and elongation of latera } \\
\text { musculature. }\end{array}$ \\
\hline Unilateral bridges & 10 on each leg & $\begin{array}{l}20 \text { breaths, } 1 \text { per repetition on each leg; exhale during bridge; inhale as } \\
\text { hips lower to ground }\end{array}$ & $\begin{array}{l}\text { Increased strength of glute } \\
\text { musculature. }\end{array}$ \\
\hline $\begin{array}{l}\text { Dead bug with } \\
\text { single leg tap down }\end{array}$ & 10 on each leg & $\begin{array}{l}20 \text { breaths, } 1 \text { per repetition on each side; inhale as leg lowers down to the } \\
\text { ground; exhale as leg returns to the } 90-90 \text { position }\end{array}$ & $\begin{array}{l}\text { Increased core strength and spi- } \\
\text { nal stability at varying degrees } \\
\text { of difficulty as limbs extend from } \\
\text { center. Focus on the principles of } \\
\text { control, center, and precision. }\end{array}$ \\
\hline Roll up & 10 & $\begin{array}{l}20 \text { breaths, } 2 \text { per repetition; inhale to } 90 \text { degrees of shoulder flexion; } \\
\text { exhale to lift back and torso off the ground to reach over toes; inhale back } \\
\text { to long sitting; exhale to slowly lower torso to the ground }\end{array}$ & $\begin{array}{l}\text { Increased segmental mobility of } \\
\text { the spine, improved concentric } \\
\text { and eccentric motor control, } \\
\text { stretch of posterior musculature } \\
\text { and spinal elongation. }\end{array}$ \\
\hline
\end{tabular}

Note: MF: Multifidus Muscle; TA: Transverse Abdominus Muscle; IO: Internal Oblique Muscle; EO: External Oblique Muscle.

Table 5: MCID and Reliability Values for The Outcomes Measures Utilized.

\begin{tabular}{|c|c|c|}
\hline Measurement & MCID Value & ICC (Inter-Rater Reliability) \\
\hline MIP & SDD*: $22 \%$ & 0.88 \\
\hline MEP & SDD*: $19 \%$ & 0.87 \\
\hline \multirow{3}{*}{ Chest wall expansion } & Upper: $>3.60$ & Upper: $0.78-0.83$ \\
\hline & Lower: $>4.40$ & Lower: $0.82-0.84$ \\
\hline & Middle: NA & Middle: NA \\
\hline Postural sway during single limb balance & Not found & 0.6 \\
\hline \multirow{8}{*}{ SF-36 } & 8.7: physical function & 0.92: physical function \\
\hline & 18.4: role physical & 0.88: role physical \\
\hline & 11.8: bodily pain & 0.91 : bodily pain \\
\hline & 6.5: general health & 0.78: general health \\
\hline & 9.3: vitality & 0.83: vitality \\
\hline & 9.4: social functioning & 0.83: social functioning \\
\hline & 15.6: role-emotional & 0.83: role-emotional \\
\hline & 5.7: mental health & 0.86: mental health \\
\hline VAS & 2 points & NA \\
\hline
\end{tabular}

Note: MCID: Minimal Clinically Important Difference; ICC: Intraclass Correlation Coefficient; SDD: Smallest Detectable Difference As A Percentage Of The Mean, * SDD Used As MCID Value Was Unattainable; MIP : Maximal Inspiratory Pressure; MEP: Maximal Expiratory Pressure; SF-36: Short Form-36 Questionnaire; VAS: Visual Analog Scale; NA: Not Applicable.

After being introduced to the basics, the patient was asked to assume the hook-lying position for instruction in diaphragmatic breathing and to complete eight repetitions of inhaling and exhaling. The therapist used tactile cues with hands around the lower rib cage at the initiation of diaphragmatic breathing to ensure the patient was achieving lateral and posterolateral ribcage expansion. Proper breathing was encouraged throughout the entire intervention, especially as it has been shown to increase electromyogram activity of important core-stabilizing muscles [14]. Movements were synchronized with breaths, with exhalation occurring during moments of elongation and stretching (Table 4). The intervention was divided into four categories and administered in the order shown in Table 5.

\section{Intervention Exercises}

Pelvic clocks. While in the hook-lying position, the patient was encouraged to imagine a clock on her lower abdomen. With that visual cue, she tilted her pelvis in every direction until each 
hour between one and 12 o'clock were achieved. The patient completed two entire cycles in the clockwise direction and then two in the counterclockwise direction.

a. Hundred: The patient assumed the 90-90 position with her head and scapulae lifted off the mat and her arms hovering above the mat at her sides. While inhaling through her nose, the patient performed five small pumps with her arms in the superior to inferior direction. Next, the patient exhaled through her mouth for five more small pumps. This cycle was repeated nine more times to achieve a total of 100 arm pumps. Diaphragmatic breathing was again encouraged to avoid dominance of her rectus abdominus and promote transverse abdominus activation.

b. Swimming: The patient assumed the prone position with all limbs lifted off the mat about six inches. A chin tuck was performed and maintained to reduce the use of cervical spine extensors. The patient swiftly lifted her right arm and left leg simultaneously before quickly switching to the opposite limbs. This alternation was completed continuously for a set of ten slow breaths. The patient was instructed to maintain core activation and elongation of the limbs throughout the motion.

c. Cat and cow: The patient assumed the quadruped position with her hands directly under her shoulders, her knees directly below her hips, and her spine in neutral. With an inhale, the patient was asked to maximally extend her spine while lifting her head and tail bone to the sky. Upon the exhale, the patient slowly flexed her back by tightening her core and bringing her belly button toward the sky and reaching her head and tail bone down to the ground. This was repeated until a total of eight repetitions were performed (Figure 4).

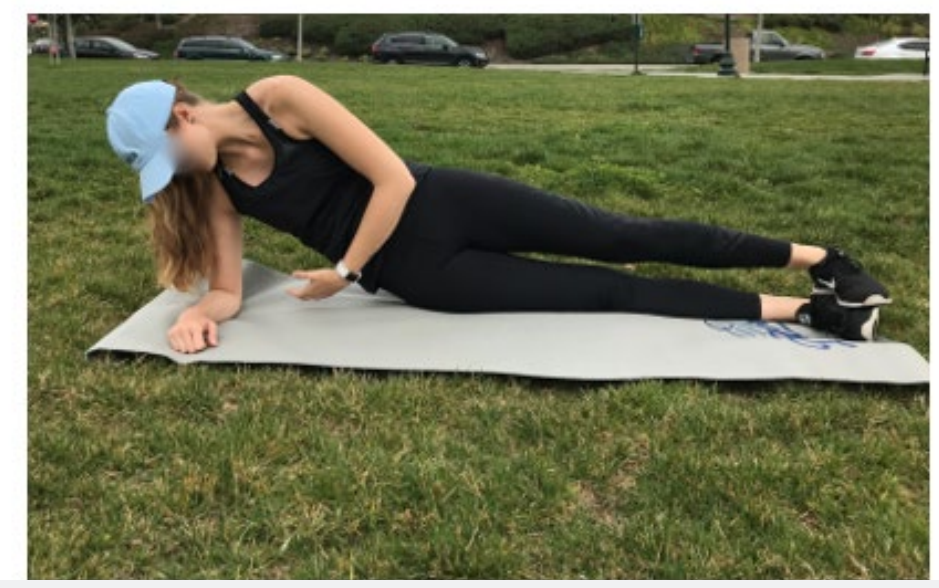

Figure 4: Starting Position of Side Plank Mermaid.

d. Standing roll-down stretch: The patient began in standing with her feet hip width apart. The patient was then asked to raise her arms straight above her head before slowly bending down toward the ground by attempting to flex one vertebra at a time. The patient then began to roll her spine back up, one vertebra at a time, until she reached her initial position with arms at her sides. The process was completed for a total of eight repetitions (Figure 5).

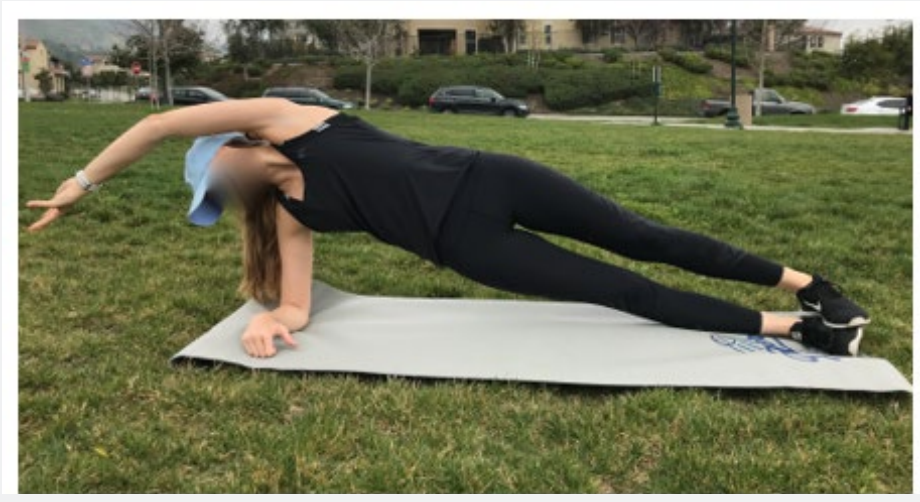

Figure 5: Ending Position of Side Plank Mermaid. 
e. Spine stretch: The spine stretch was completed with the patient seated on the floor with legs positioned in a narrow "V". The patient began sitting tall, with her spine elongated. The patient was asked to inhale and then exhale while reaching her arms straight forward and pulling her belly button back, but with the top of her head forward. With an inhale the patient rotated her spine to the right by reaching her right arm back behind her, and with an exhale she reached her left arm toward her right toes. The patient was then asked to take a big inhale into the left thorax and exhale reaching farther with her left arm for a deeper stretch. An inhale was used to transition to left rotation and an exhale to reach the right arm past the left toes. Again, the patient was asked to inhale into her right thorax and exhale for a deeper stretch by reaching farther with her right arm. The patient then went back to center, rolled her spine up and ended in the starting position. This series was completed seven more times for a total of eight repetitions (Figure 6).

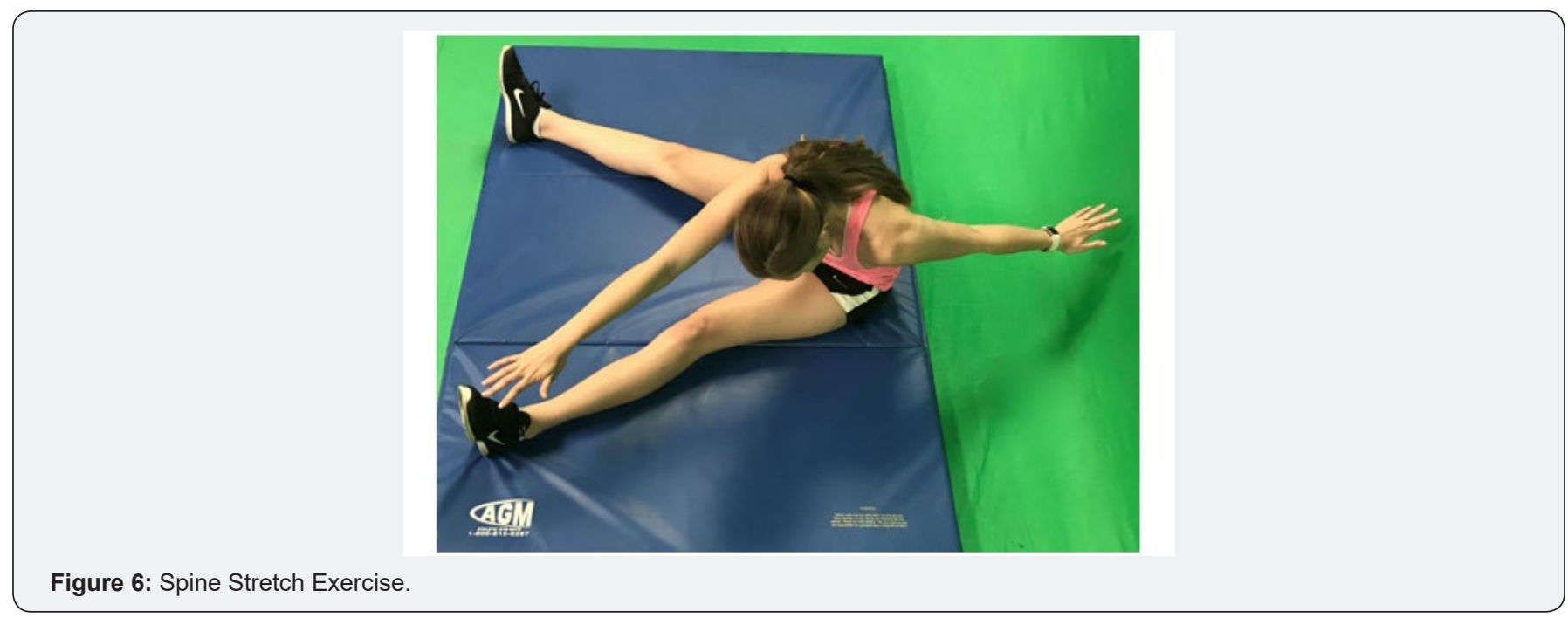

f. Single leg stretches: In a supine position, the patient lifted her right leg straight up into the air, while the other leg hovered over the ground. With both hands, the patient reached for the back of her right thigh while gently lifting her head and shoulders off the ground. With an inhale, the patient switched the position of her legs and with an exhale, she pulled on the back of her left thigh for a hamstring stretch. This alternation was continued for both bilateral hamstrings stretches and core activation until eight repetitions were performed on each side (Figure 7).

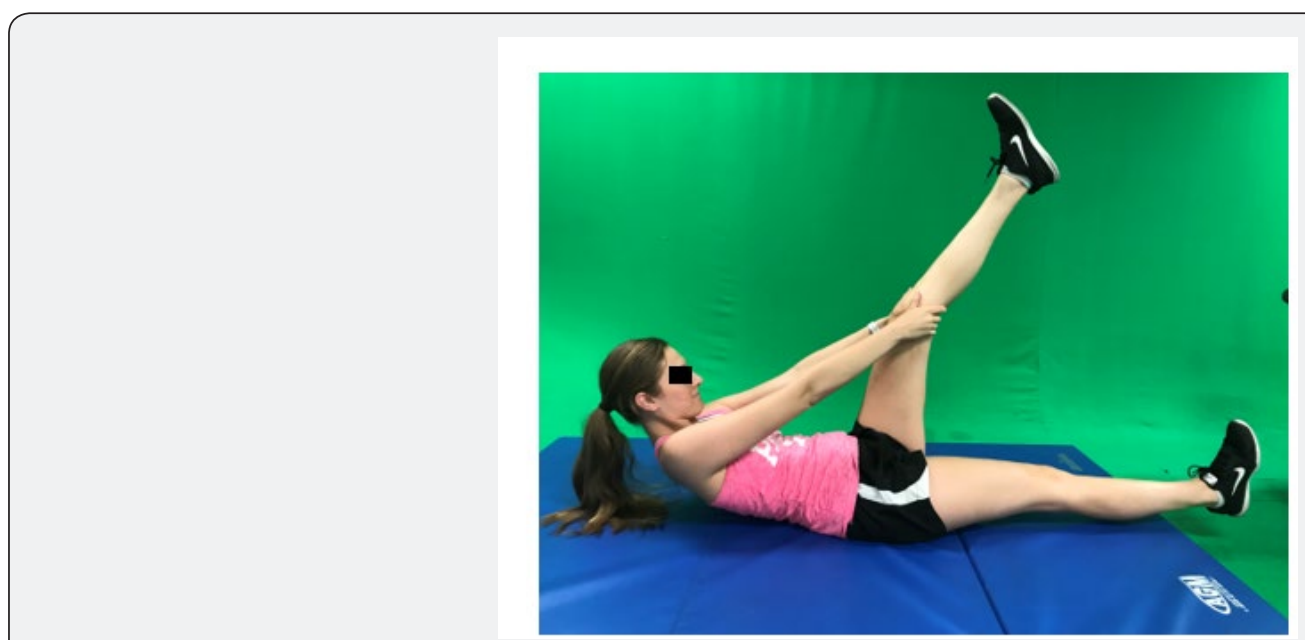

Figure 7: Single Leg Stretch Exercise.

g. $\quad 90-90$ side to side: While in supine with both knees and hips at $90^{\circ}$ of flexion and arms out to her sides, the patient was instructed to inhale to gently lower her knees to her right side and then exhale to bring them back to center.
The patient then inhaled again to bring her knees to her left side and then exhaled to bring them back to center. Eight repetitions were completed on each side. 
h. Mermaid: The patient was instructed to assume a sidesit position with her right leg externally rotated and adducted in front of her with her knee flexed and her left leg internally rotated and abducted to her side with her knee flexed and her foot near her back. The patient lifted both arms out to her sides before reaching to her right, with her right arm grazing the ground and side-bending right with her left arm lifting up and over her body. During this motion, the patient exhaled. The patient was then encouraged to use her core to return her body to center while inhaling and then reach her right arm up over her body for a right side stretch during an exhale. The patient inhaled again into the right side of her body and then exhaled to return to the starting position. This motion was completed for a total of eight repetitions before switching positions to the opposite side.

i. Quadruped twist: The patient first assumed the quadruped position, this time with her right arm internally rotated with fingers facing the middle. Upon an exhale, the patient unloaded her left arm, externally rotated it and reached toward the right underneath her right arm. Then, the patient took a big inhale into her left rib cage and exhaled to reach as far to the right as she could. The patient inhaled and retuned to quadruped. The patient then performed the same motion in the opposite direction with opposite motions of her arms. Eight repetitions were completed on both sides.

j. Quadruped bird-dog: While in quadruped, the patient was instructed to lift her right arm and left leg up at the same time, while maintaining a neutral pelvis and stable spine. A chin tuck was encouraged to prevent over-extension at the cervical spine. The patient slowly lowered her limbs and repeated the action with her left arm and right leg. A total of eight repetitions on both sides were performed.

k. Side plank mermaid: The patient assumed a right-side plank position, with feet stacked one upon the other, elbow directly under shoulder, and spine straight. With an inhale, the patient lowered her hips until just before her right hip touched the ground. With an exhale, she pushed her hips up away from the ground and reached her left arm over her body to encourage a left side stretch. The patient repeated this motion seven more times before turning to her left side to complete another set of eight repetitions.

l. Unilateral bridges: The patient began in the hooklying position before elevating her left leg into the sky with her left hip at $90^{\circ}$ of flexion. The patient then performed a bridging motion by extending her right hip until achieving 0 o of flexion. The patient repeated this motion for a total of eight repetitions without compensations of pelvic rotation or excessive lumbar lordosis.

m. Dead bug with single-leg tap down: The patient began in the hook-lying position. The patient was instructed to lift both legs into the 90-90 position and then extend her arms up into the air, perpendicular to her body. While activating the core and maintaining a neutral spine, the patient gently lowered one leg to tap her heel on the ground and then slowly brought it back up to $90^{\circ}$ of hip flexion. The motion was repeated on the opposite side to complete one repetition. A total of eight repetitions were completed.

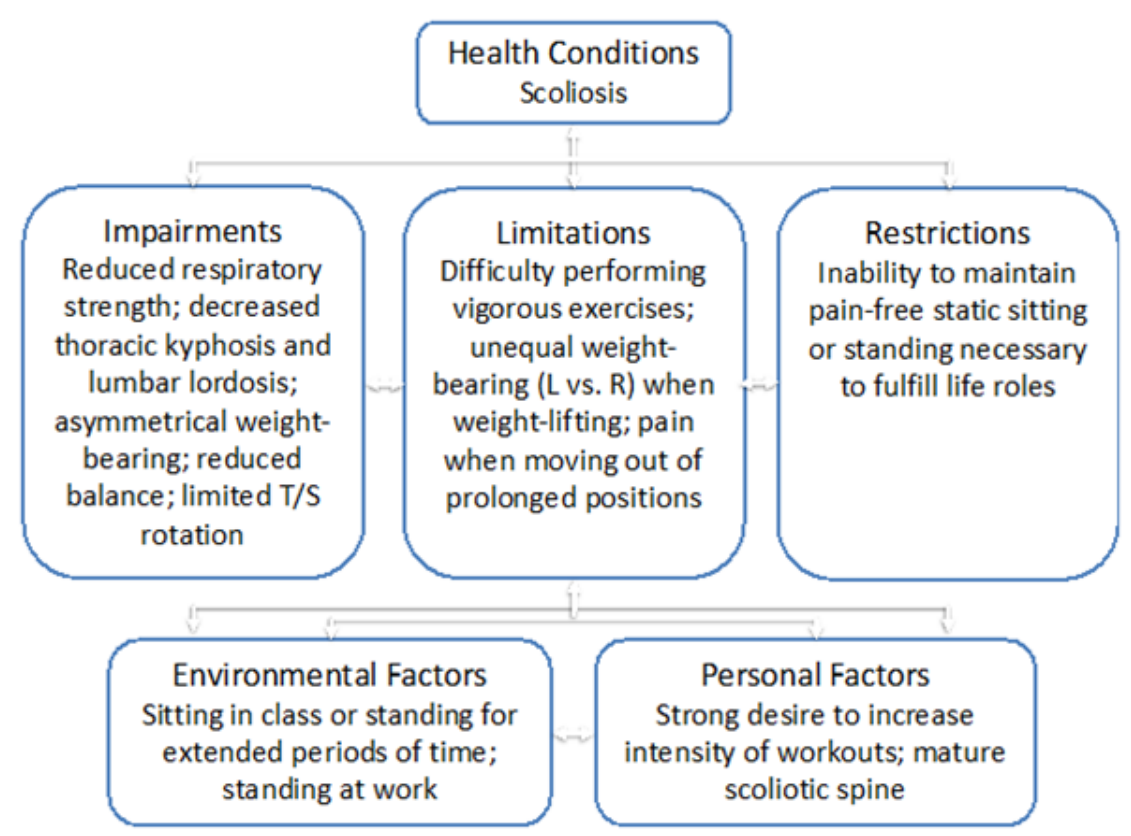

Figure 8: International Classification of Functioning, Disability and Health (ICF) Model. T/S: Thoracic Spine. 
n. Roll up: The patient began in supine with legs extended down and arms extended up overhead. With an inhale, the patient lifted her arms to $90^{\circ}$ of shoulder flexion, then with an exhale, the patient used her core to roll her torso up off the ground while reaching her arms forward over her legs, pulling her belly button back. With an inhale, the patient extended her back to assume an upright position for spinal elongation. Then, slowly and with control, the patient exhaled to lower her torso back down to the ground, one vertebra at a time. A total of eight repetitions were completed (Figure 8). Progressions were implemented at the start of each week. At the start of week two, repetitions were increased from eight to 10 for all exercises other than the warm-up. By increasing the number of repetitions, the demand on the muscles was also increased. In addition, the hundred exercise was specifically progressed by performing the exercises with the hips at $45^{\circ}$ of flexion and knees extended, rather than both the hips and knees in $90^{\circ}$ of flexion. In this position, the core musculature is forced to work harder to maintain a neutral spine, which increases the benefit of the exercise. The unilateral bridge was progressed not only with increased repetitions, but with the addition of a static bridge and lifting and lowering (flexion and extension) of the unloaded leg for a total of 10 repetitions. This progression increased the amount of time the hip extensors were under tension, thus increasing the demand.

o. At the start of week three, the same exercises were increased from 10 repetitions to 12 . The patient reported that she did not feel as challenged by the exercise regimen as she was at the beginning, thus the therapist implemented more progressions for week four. At the start of the last week, the quadruped bird-dog exercise was progressed to hip extensions from a full plank position. The patient was observed to ensure no compensations, such as pelvic rotation or lumbar extension, were performed. The side plank mermaid series was progressed to a side plank with the grounding arm extended. This increased the demand on the core as well as on the musculature around the scapula and glenohumeral joint.

p. The difficulty of the unilateral bridges was increased by introducing a Swiss ball to challenge the patient's stability, and 12 repetitions of the bridges were performed without static lifting and lowering of the elevated leg. The final progression occurred as a 10-pound ball was introduced for the roll up exercise. This exercise was altered as the patient was no longer instructed to reach over her legs for a spine stretch, but rather to achieve full spinal elongation in the upright long-sitting posture. Throughout all the progressions described, the patient reported no increase in symptoms or discomfort. In addition, the subject continued her regular exercise routine of lifting weights (bench press, pull-ups, bicep curls, and leg presses) five times a week, for about one hour per session during the entirety of treatment.

\section{Outcomes}

The patient was able to perform the exercise regimen without any pain reproduction and was able to progress without compromising form. During the first two sessions, the therapist was present to explain the exercises, provide manual and verbal cues, and correct movements to optimize every exercise. The patient quickly demonstrated independence with the regimen and was able to perform the sessions with supervision only. When the progression was implemented, the therapist ensured the patient continued to execute the exercises successfully.

Because of the patient's complaint of impaired respiratory function, especially during vigorous activity, CWE and respiratory muscle strength were assessed. These measurements were taken to detect any restrictions that could contribute to reduced respiratory function (Table 1,2). It has been reported that CWE declines with age in individuals with scoliosis, even if the Cobb angle does not progress [15]. In addition, Reddy et al. [16] discovered that upper and lower chest expansion measurements have a strong correlation with vital capacity. The post-test demonstrated improvements in the patient's upper and lower chest mobility by $1.75 \mathrm{~cm}$ (Table 1), but a minimal clinically important difference (MCID) was not available in the literature (Table 2).

The patient's inspiratory muscle strength improved significantly as her follow-up MEP score improved by $23 \%$, which exceeded the smallest detectable difference of $22 \%$. Though her inspiratory muscle strength improved by $15 \%$, it did not hit the threshold of 19\% (Table 1,2). Maximal inspiratory and expiratory strength are the most common and least invasive measurements of respiratory muscle strength, which had been shown to contribute to reduced ventilation, inadequate gas exchange, and insufficient oxygen delivery to tissues when low scores are illustrated [7]. Respiratory muscle strength has also been associated with vital capacity and lung function [8].

Because the patient presented with postural asymmetries and reported functional asymmetries, symmetry of weightbearing during a squat was measured by comparing weight distribution through the left and right sides of the patient's body (Table 1). Values for reliability and MCID were not found in the literature, but the patient's progress appeared to be of great significance as weight distribution improved from 30:70 to $50: 50$ (Table 1 ).

One of the same force plates was then used to detect postural sway during single limb balance (Table 2). The patient's CoP for the left and right SLS post-tests decreased to $5.39 \mathrm{~mm}$ and $4.39 \mathrm{~mm}$, respectively. The patient's total excursion decreased by $112.66 \mathrm{~mm}$ during the left SLS to $829.62 \mathrm{~mm}$. The patient's final right SLS total excursion was 672.31, demonstrating a decrease of $316.5 \mathrm{~mm}$. The literature did report MCID values but suggested that increases in CoP distance and decreases in total excursion can indicate improved balance as it shows the subject 
has a greater ability to move further outside his or her base of support while requiring fewer overall movements to maintain balance. The patient also improved in her SLS time with eyes closed, bilaterally. The greatest improvement was shown in her right SLS time, which increased by 6.1 seconds. An improvement of 3.2 seconds was also seen in her left SLS.

The patient's reported pain levels significantly improved by meeting the MCID score of 2 on the Visual Analog Scale. At the follow-up, she reported a decrease in low back pain from $7 / 10$ to $5 / 10$ with prolonged positions (Table 2). Data from the followup testing is outlined in (Table 1,3), which display initial and follow-up measurements. The patient demonstrated significant improvements in her respiratory function, functional symmetry, balance, and pain intensity.

\section{Discussion}

The main emphases of this exercise regimen were segmental stability and mobility of the core, which helps prevent injuries and increase physical performance. Additionally, spinal stability is of the utmost importance in the scoliotic population $[17,18]$ discovered increased instability in people with scoliosis by measuring pressure variations in multiple areas of the cervical, thoracic, and lumbar spine during various motions, such as flexion, extension, and rotation The warm-up exercises outlined in table 3 encouraged mobility of the pelvis, activation of the TA and multifidus (MF) muscles, as well continual use of diaphragmatic breathing during the exercises. Pelvic mobility is important as it greatly affects the posture of the spine [19]. Because individuals with back pain have been observed to have delayed onset of TA muscle activation and atrophied MF muscles, the hundred and swimming exercises were used to promote improved activation of the TA and MF muscles, respectively $[20,21]$.

The stretches outlined in Table 1 were chosen because of their effects on restoring thoracic kyphosis, promoting spinal elongation, and increasing flexibility of the posterior chain. The asymmetrical exercises were implemented to encourage equal activation of muscles on either side of the body [22]. showed that asymmetrical exercises performed in the context of weightlifting were successful in targeting the muscles of the concavity of the spine, which are often less active. In addition, most exercises that were performed assisted in increasing flexibility of the spine, hamstrings, and lateral portions of the spine and thorax. The mermaid and quadruped twist both involved twisting motions that closed one side while elongating the other side. During these activities, the patient was asked to breathe deeply into the side of elongation to increase lung volume, promote mobility, and increase CWE. This specificity was enforced with each repetition.

The final symmetrical exercise was used to restore a proper balance of muscle activation, practice muscular control, and incorporate fluidity with concentric and eccentric muscle contractions and diaphragmatic breathing. One possible limitation in this case study is researcher bias. Because the individual conducting the intervention was the same person who recorded and analyzed the data, there was potential for biased results. In addition, the patient's involvement in other physical activity could have contributed to the outcomes assessed because of the nature of general strength training and its effects on the musculoskeletal and respiratory systems. Lastly, there was no long-term follow-up performed to determine if the beneficial results continued past the week after the intervention. Further research using a larger number of young adult subjects is warranted. The intervention should also be conducted in more controlled circumstances to decrease the effects of confounding factors on related outcome measures. All in all, this mat Pilates protocol was successful in this patient with AIS, but as it involved only one case, the results may not be generalizable to the entire young adult population.

\section{Acknowledgments}

I wish to thank my professors at Azusa Pacific University for teaching with the spirit of excellence, leading by example, and for their constant support. I would specifically like to thank Dr. Marshall Le Moine for his mentorship and assistance in the development of this study. Finally, I wish to acknowledge Dr. Christopher Patterson for providing me with the use of his laboratory equipment and assisting with data calculations and interpretation.

\section{References}

1. Gallant JN, Morgan CD, Stoklosa JB, Gannon SR, Shannon CN, et al. (2018) Psychosocial difficulties in adolescent idiopathic scoliosis: Body image, eating behaviors, and mood disorders. World Neurosurg 116: 421-432.

2. Altaf F, Gibson A, Dannawi Z, Noordeen H (2013) Adolescent idiopathic scoliosis. British Medical Journal 346.

3. Cheung PW, Wong CK, Cheung JP (2018) An insight into the healthrelated quality of life of adolescent idiopathic scoliosis patients undergoing bracing, observation, and previously braced. Spine 44(10): E596-E605.

4. Maruyama T, Grivas TB, Kaspiris A (2011) Effectiveness and outcomes of brace treatment: A systematic review. Physiother Theory Pract 27(1): 26-42.

5. Romano M, Minozzi S, Bettany-Saltikov J, Zaina F, Chockalingam N, et al. (2012) Exercises for adolescent idiopathic scoliosis. Cochrane Database of Systematic Reviews (8): CD007837.

6. Park JH, Jeon HS, Park HW (2018) Effects of the Schroth exercise on idiopathic scoliosis: A meta-analysis. Eur J Phys Rehabil Med 54(3): 440-449.

7. Sclauser Pessoa IM, Franco Parreira V, Fregonezi GA, Sheel AW, Chung F, et al. (2014) Reference values for maximal inspiratory pressure: A systematic review. Can Respir J 21(1): 43-50.

8. Evans JA, Whitelaw WA (2009) The assessment of maximal respiratory mouth pressures in adults. Respir Care 54(10): 1348-1359.

9. Mohan V, Dzulkifli NH, Justine M, Haron R, Rathinam C (2012) Intrarater reliability of chest expansion using cloth tape measure technique. Bangladesh Journal of Medical Science 11(4): 307-311. 
10. Beaulieu M, Toulotte C, Gatto L, Rivard CH, Teasdale N, et al. (2009) Postural imbalance in non-treated adolescent idiopathic scoliosis at different periods of progression. Eur Spine J 18(1): 38-44.

11. da Silva RA, Bilodeau M, Parreira RB, Teixeira DC, Amorim CF (2013) Age-related differences in time-limit performance and force platformbased balance measures during one-leg stance. J Electromyogr Kinesiol 23(3): 634-639.

12. Bohannon RW, Larkin PA, Cook AC, Gear J, Singer J (1984) Decrease in timed balance test scores with aging. Physical Therapy 64(7): 10671070 .

13. Burholt V, Nash P (2011) Short form 36 (SF-36) health survey questionnaire: Normative data for Wales. Journal of Public Health 33(4): 587-603.

14. Kim ST, Lee JH (2017) The effects of Pilates breathing trainings on trunk muscle activation in healthy female subjects: A prospective study. J Phys Ther Sci 29(2): 194-197.

15. Weiss HR (2012) Physical therapy intervention studies on idiopathic scoliosis-review with the focus on inclusion criteria 1. Scoliosis 7(1): 4 .

16. Reddy RS, Alahmari KA, Silvian PS, Ahmad IA, Kakarparthi VN, et al (2019) Reliability of chest wall mobility and its correlation with lung functions in healthy nonsmokers, healthy smokers, and patients with COPD. Can Respir J.

17. Panjabi MM (2003) Clinical spinal instability and low back pain. Journal of Electromyography and Kinesiology 13(4): 371-379.

18. Luo HJ, Lin SX, Wu SK, Tsai MW, Lee SJ (2017) Comparison of segmental spinal movement control in adolescents with and without idiopathic scoliosis using modified pressure biofeedback unit. PloS One 12(7): $1-12$.

19. Muscolino JE, Cipriani S (2004) Pilates and the powerhouse. Journal of Bodywork and Movement Therapies 8(1): 15-24.

20. Hodges PW (2001) Changes in motor planning of feedforward postural responses of the trunk muscles in low back pain. Experimental Brain Research 141(2): 261-266.

21. Yoshihara K, Shirai Y, Nakayama Y, Uesaka S (2001) Histochemical changes in the multifidus muscle in patients with lumbar intervertebral disc herniation. Spine 26(6): 622-626.

22. Schmid AB, Dyer L, Böni T, Held U, Brunner F (2010) Paraspinal muscle activity during symmetrical and asymmetrical weight training in idiopathic scoliosis. J Sport Rehabil 19(3): 315-327.

Your next submission with Juniper Publishers
will reach you the below assets
- Quality Editorial service
- Swift Peer Review
- Reprints availability
- E-prints Service
- Manuscript Podcast for convenient understanding
- Global attainment for your research
- Manuscript accessibility in different formats
( Pdf, E-pub, Full Text, Audio)
- Unceasing customer service
Track the below URL for one-step submission
https://juniperpublishers.com/online-submission.php

DOI: 10.19080/JYP.2019.08.555734 